\title{
Analytical investigation of reinforced concrete panels subjected to high velocity impacts
}

\author{
E. Galuta ${ }^{1}$, M. Majeed ${ }^{2}$ \& W. Reghig ${ }^{1}$ \\ ${ }^{1}$ Civil Engineering Department, University of Tripoli, Libya \\ ${ }^{2}$ Civil Engineering Department, University of Ottawa, Canada
}

\begin{abstract}
This paper represents the analytical investigation of the performance of reinforced concrete structures retrofitted with steel and non-metallic grids against high velocity projectile $(0.50 \mathrm{cal}$. Bullet). In order to investigate the performance of the retrofitted structures, a number of concrete slab panels with the dimensions of $600 \times 600 \times 100 \mathrm{~mm}$ retrofitted with steel mesh, glass fibres, and polyethylene grids were analytically investigated using ANSYS AUTODYN 3D. Different retrofit schemes using different layers of grids, changing the location and numbers of these layers inside the concrete panels were implemented in this investigation. The residual velocity of bullet, kinetic energy of fragments and penetration depth were obtained and compared for the retrofitted structures. The analytical investigation showed that the proposed retrofit provided significant impact resistance capacity in comparison to regular reinforced concrete slab panels. Furthermore, the number and location of layers for the grids had a significant effect on reducing the velocity of the bullet and kinetic energy of fragments.

Keywords: impact, penetration, retrofitting, projectile, concrete, steel mesh and non-metallic grids.
\end{abstract}

\section{Introduction}

Concrete is the most commonly used construction material and a knowledge of its vulnerability to impact is considered to be very important when considering the design of the structure. Extensive research has been carried out by Zhang et al. [1], Vossoughi et al. [2] and Beppu et al. [3] to investigate the performance of impact resistance of concrete structures against high velocity projectile. High velocity projectile impact can cause local and global damage to the structure. Local 
damage can lead to concrete fragmentation from the front surface, projectile penetration into the target, scabbing of concrete from the back face, and finally, perforation through the target. The extent of damage depends on a variety of factors, such as impact velocity, mass, geometry, material properties of the projectile, and the material properties and thickness of the target.

Different techniques to enhance the impact resistance capacity of concrete structures against high speed projectile can be developed. One of the techniques to enhance the concrete properties is use of Ferro-cement. Ferro-cement improves the resistance of concrete structures to fragmentation and increases the ability of the concrete structures to withstand impact loads $[4,5]$. Another technique is to use non-metallic grids as protective layers to provide more effective reinforcement for absorbing energies generated by high speed impact [6].

This paper employs the explicit dynamic finite element code AUTODYNE 3D to investigate the performance of reinforced concrete panels retrofitted with metallic and non-metallic grids against high speed impact loading and to find the best retrofitting scheme (protective layer) in order to reduce the residual projectile speed and the resulting damage.

\section{Numerical simulation}

All the numerical investigations presented in this paper were performed by AUTODYN 3D v.14.5 using Lagrange processor. The interaction of the bullet with the concrete panel was achieved using the gap interaction logic [7]. The initial velocity of the bullet was $640 \mathrm{~m} / \mathrm{sec}$ in $\mathrm{Z}$ direction. The bullet was assumed not to impact the reinforcement bars. The boundary conditions for all concrete panels in all retrofits were assumed to be fixed, i.e. zero velocities in $\mathrm{x}, \mathrm{y}$ and $\mathrm{z}$ directions.

\subsection{Geometric modelling}

\subsubsection{Reinforced concrete panel (RC)}

A concrete panel with dimensions of $600 \times 600 \times 100 \mathrm{~mm}$ and a compressive strength of $35 \mathrm{MPa}$ was used as a target. The panel is reinforced with $10 \mathrm{~mm}$ diameter hot rolled deformed steel bars in two perpendicular directions with spacing of $200 \mathrm{~mm}$ between the bars. Details of the reinforced concrete panel are shown in Figure 1. A total of 36,000 Lagrangian elements were used to simulate the concrete portion of the panel, while the reinforcement steel bars were represented by 1920 beam elements. The geometry of the concrete panel was defined to have a fine mesh in the center (where the bullet hits the panel) and coarser mesh away from its centre. Figure 2 illustrates the geometric modelling used for the reinforced concrete panel. 


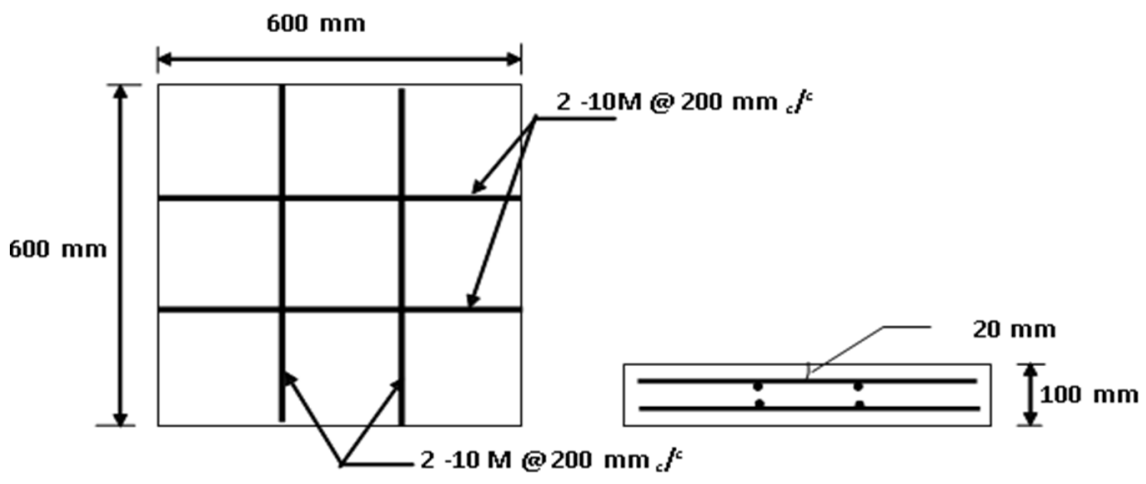

Figure 1: Details of RC panel.
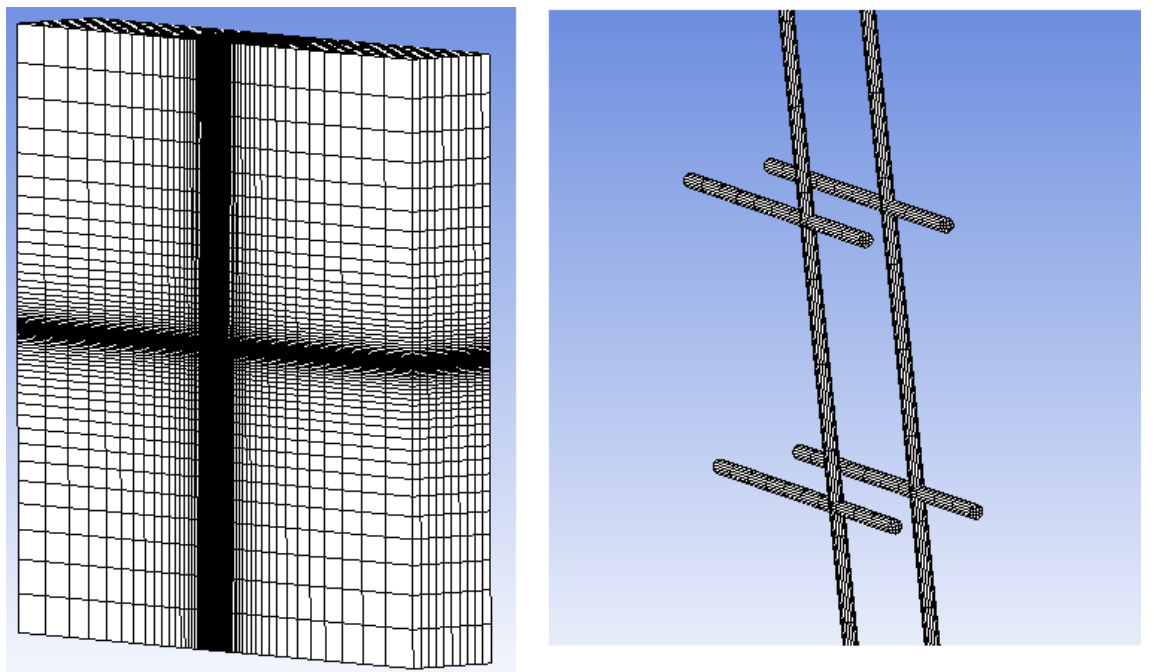

Figure 2: Geometric modeling for concrete panel and reinforcement bars.

\subsubsection{Bullet}

The bullet (projectile) was modeled to simulate the actual geometric shape and dimensions of a real .50 caliber barrel bullet as close as possible. A $60 \mathrm{~mm}$ ogivenosed bullet was used to hit the concrete panel at the centre. The model consists of two sections; outer copper jacket and inner lead core. 1200 Lagrangian elements were used to simulate the whole bullet. Details of mesh and bullet components are shown in Figure 3. 

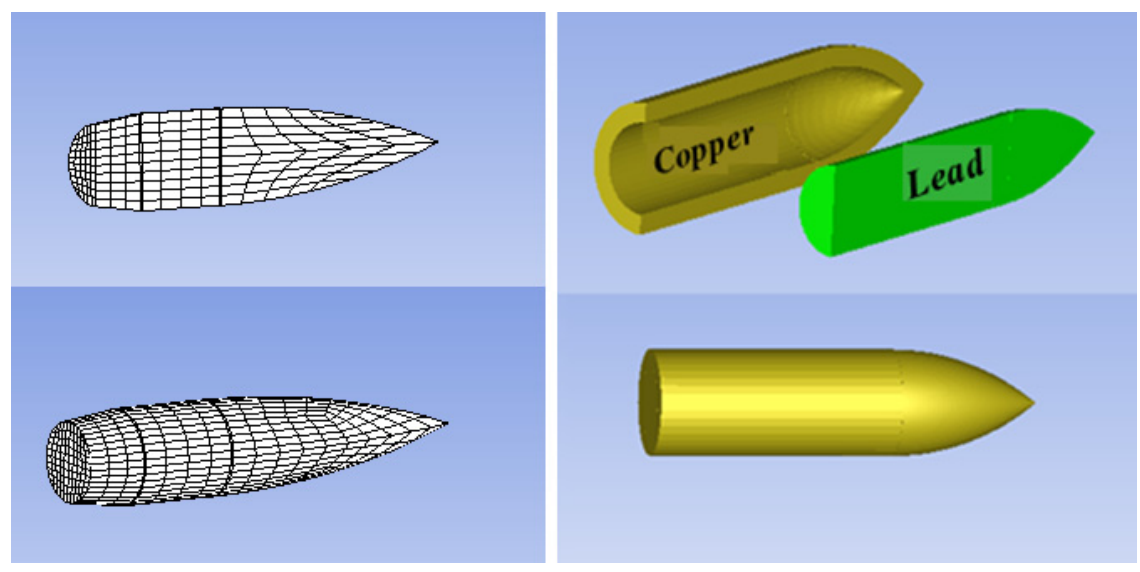

Figure 3: Bullet mesh and components.

\subsubsection{Metallic and nonmetallic girds}

Different types of grids made of steel, glass fiber and polyethylene were used for the retrofitting technique. The steel grid of style (1/2 in \#16) and AISI 4340 type was used with strand width and thickness of $2.2 \mathrm{~mm}$ and $1.5 \mathrm{~mm}$ respectively. More details are shown in Figure 4.

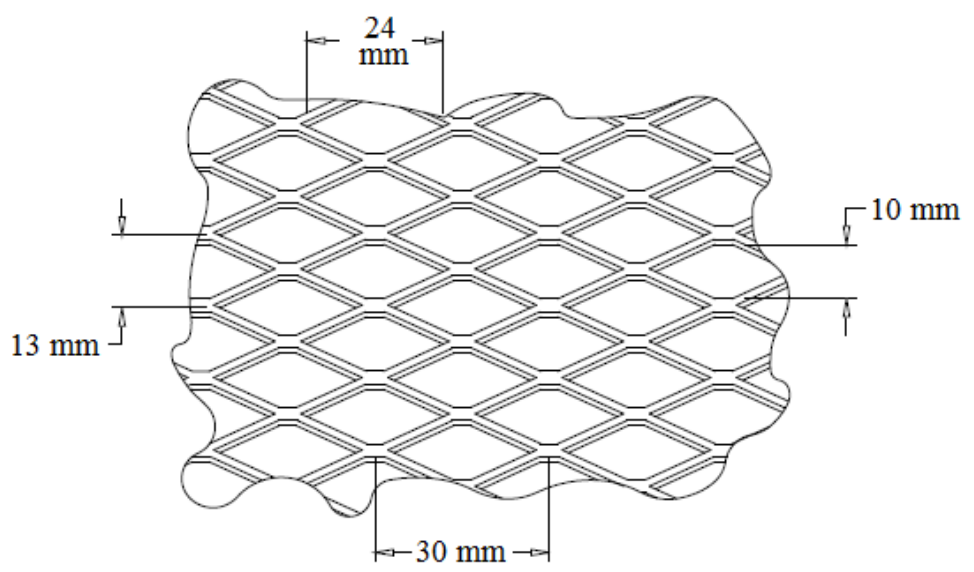

Figure 4: Geometry of the steel grid.

High density polyethylene and glass fiber grids were used to construct the other types of protection systems. Material properties of both grids can be found in [6]. The non-metallic grids, polyethylene and glass fiber, were represented in AUTODYN simulation by two dimensional beam elements. Details of the geometry and dimensions of non-metallic grids are shown in Figure 5. 


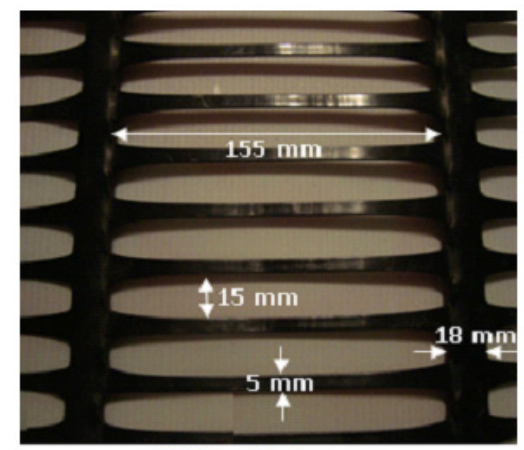

Polyethylene

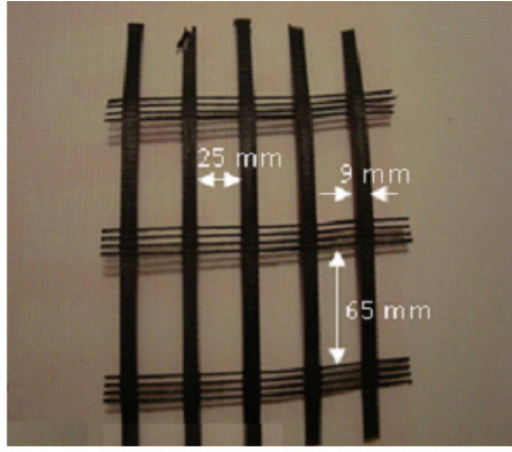

Glass Fiber

Figure 5: Geometry and dimensions of non-metallic grids.

\subsection{Material models}

The material model has typically four basic types of information to be specified for each material; Equation of State (EOS), Strength, Failure and Erosion Models. All parameters of the material models used for the numerical simulation are defined in AUTODYN material library. Values of material models adopted in the simulation are summarized in Table 1.

Table 1: $\quad$ Summary of material models.

\begin{tabular}{|l|l|l|l|l|}
\hline Material & EOS & Strength & Failure & Erosion \\
\hline Concrete & P-Alpha & RHT Concrete & $\begin{array}{l}\text { RHT } \\
\text { Concrete }\end{array}$ & $\begin{array}{l}\text { Geometric } \\
\text { Strain }\end{array}$ \\
\hline Steel 4340 & Linear & Johnson Cook & Plastic Strain & $\begin{array}{l}\text { Geometric } \\
\text { Strain }\end{array}$ \\
\hline Lead & Shock & $\begin{array}{l}\text { Steinberg } \\
\text { Guinan }\end{array}$ & None & None \\
\hline Glass Fiber & Linear & Elastic & $\begin{array}{l}\text { Principal } \\
\text { Strain }\end{array}$ & $\begin{array}{l}\text { Geometric } \\
\text { Strain }\end{array}$ \\
\hline Polyethylene & Linear & Elastic & $\begin{array}{l}\text { Principal } \\
\text { Strain }\end{array}$ & $\begin{array}{l}\text { Geometric } \\
\text { Strain }\end{array}$ \\
\hline
\end{tabular}

\subsection{Retrofitting scheme}

The simulations were performed for each type of panel-retrofit. The panel identification and retrofit layers are shown in Table 2. 
Table 2: $\quad$ Retrofitting identification and layers.

\begin{tabular}{|l|l|l|}
\hline No & $\begin{array}{l}\text { Panel } \\
\text { identification }\end{array}$ & Retrofit layer \\
\hline 1 & RC & Reinforced Concrete (Control Panel) \\
\hline 2 & $1 \mathrm{GF}-\mathrm{C}$ & 1 Layer of Glass Fiber at the Centre \\
\hline 3 & $1 \mathrm{GF}-\mathrm{R}$ & 1 Layer of Glass Fiber at the Rear \\
\hline 4 & $1 \mathrm{GF}-\mathrm{F}$ & 1 Layer of Glass Fiber at the Front \\
\hline 5 & $2 \mathrm{GF}-\mathrm{C}$ & 2 Layers of Glass Fiber at the Centre \\
\hline 6 & 2GF-C-R & 2 Layers of Glass Fiber at the Centre and Rear \\
\hline 7 & $1 \mathrm{PE}-\mathrm{C}$ & 1 Layer of Polyethylene at the Centre \\
\hline 8 & $1 \mathrm{PE}-\mathrm{R}$ & 1 Layer of Polyethylene at the Rear \\
\hline 9 & $1 \mathrm{PE}-\mathrm{F}$ & 1 Layer of Polyethylene at the Front \\
\hline 10 & 2PE-C & 2 Layers of Polyethylene at the Centre \\
\hline 11 & $1 \mathrm{SM}-\mathrm{C}$ & 1 Layer of Steel Mesh at the Centre \\
\hline 12 & $1 \mathrm{SM}-\mathrm{R}$ & 1 Layer of Steel Mesh at the Rear \\
\hline 13 & $1 \mathrm{SM}-\mathrm{F}$ & 1 Layer of Steel Mesh at the Front \\
\hline 14 & $2 \mathrm{SM}-\mathrm{C}$ & 2 Layers of Steel Mesh at the Centre \\
\hline
\end{tabular}

\section{Results and discussion}

Numerical investigation for 14 different panels were performed and the responses in terms of kinetic energy and residual velocity of bullet, maximum speed and kinetic energy of fragments were determined. The ability of the retrofit system to resist and/or improve the protection of the concrete panel was measured by the reduction in the residual velocity of bullet and fragments after penetration.

\subsection{Kinetic energy and residual velocity of bullet}

Table 3 represents a comparison between the bullet residual velocity and kinetic energy for different retrofit systems. The results indicated that the protective grids succeeded in reducing the residual velocities by $2.4 \%$ to $88.7 \%$, when compared to that of the controlled panel. It can be seen that the location of the retrofit layers had significant effects on the dissipation of bullet kinetic energy and reduction of bullet velocity. For panels with one protective layer, better results were obtained when one protective layer located at the center of the panel was used. However, glass fiber showed a slight difference in results when the layers were located at the center and at rear of the panel.

The effect of the number of protective layers was investigated using four retrofits; two layers of glass fiber at centre (2GF-C), two layers of glass fiber at center and rear of the panel (2GF-C-R), two layers of polyethylene at centre (2PE$\mathrm{C})$ and two layers of steel mesh at centre (2SM-C). The maximum reduction in the velocities was achieved with the utilization of (2GF-C-R), where the reduction in the velocity was $88.7 \%$. The protective layer (2GF-C-R) showed the best performance and sustained the highest energy absorption compared with the other retrofits. The kinetic energy of the bullet was reduced by $98 \%$. 
Table 3: Retrofitting effect on kinetic energy and residual velocity of bullet.

\begin{tabular}{|c|c|c|c|c|c|}
\hline No. & Name & $\begin{array}{c}\text { Bullet residual } \\
\text { kinetic energy } \\
(\mathrm{j})\end{array}$ & $\begin{array}{c}\text { Kinetic } \\
\text { energy } \\
\text { reduction } \\
\%\end{array}$ & $\begin{array}{c}\text { Residual } \\
\text { velocity of } \\
\text { bullet } \\
(\mathrm{m} / \mathrm{s})\end{array}$ & $\begin{array}{c}\text { Bullet } \\
\text { velocity } \\
\text { reduction } \\
\%\end{array}$ \\
\hline 1 & $\mathrm{RC}$ & 2.24 & --- & 170.3 & --- \\
\hline 2 & $1 \mathrm{GF}-\mathrm{F}$ & 1.29 & $42.4 \%$ & 137.3 & $19.4 \%$ \\
\hline 3 & $1 \mathrm{GF}-\mathrm{C}$ & 0.90 & $59.8 \%$ & 114.5 & $32.7 \%$ \\
\hline 4 & $1 \mathrm{GF}-\mathrm{R}$ & 0.91 & $59.0 \%$ & 115.0 & $32.4 \%$ \\
\hline 5 & $2 \mathrm{GF}-\mathrm{C}$ & 0.20 & $91.0 \%$ & 54.2 & $68.2 \%$ \\
\hline 6 & $2 \mathrm{GF}-\mathrm{C}-\mathrm{R}$ & 0.03 & $98.0 \%$ & 19.2 & $88.7 \%$ \\
\hline 7 & $1 \mathrm{PE}-\mathrm{F}$ & 1.89 & $15.6 \%$ & 165.8 & $2.6 \%$ \\
\hline 8 & $1 \mathrm{PE}-\mathrm{C}$ & 1.65 & $26.3 \%$ & 155.1 & $8.9 \%$ \\
\hline 9 & $1 \mathrm{PE}-\mathrm{R}$ & 1.89 & $15.3 \%$ & 166.2 & $2.4 \%$ \\
\hline 10 & $2 \mathrm{PE}-\mathrm{C}$ & 1.29 & $42.1 \%$ & 137.3 & $19.4 \%$ \\
\hline 11 & $1 \mathrm{SM}-\mathrm{F}$ & 1.84 & $17.8 \%$ & 163.4 & $4.0 \%$ \\
\hline 12 & $1 \mathrm{SM}-\mathrm{C}$ & 1.75 & $21.9 \%$ & 159.5 & $6.3 \%$ \\
\hline 13 & $1 \mathrm{SM}-\mathrm{R}$ & 1.90 & $15.4 \%$ & 166.1 & $2.4 \%$ \\
\hline 14 & $2 \mathrm{SM}-\mathrm{C}$ & 1.45 & $35.3 \%$ & 145.2 & $14.7 \%$ \\
\hline
\end{tabular}

Figure 6 depicts the residual velocity of the bullet for panels retrofitted with one protective layer at different locations.

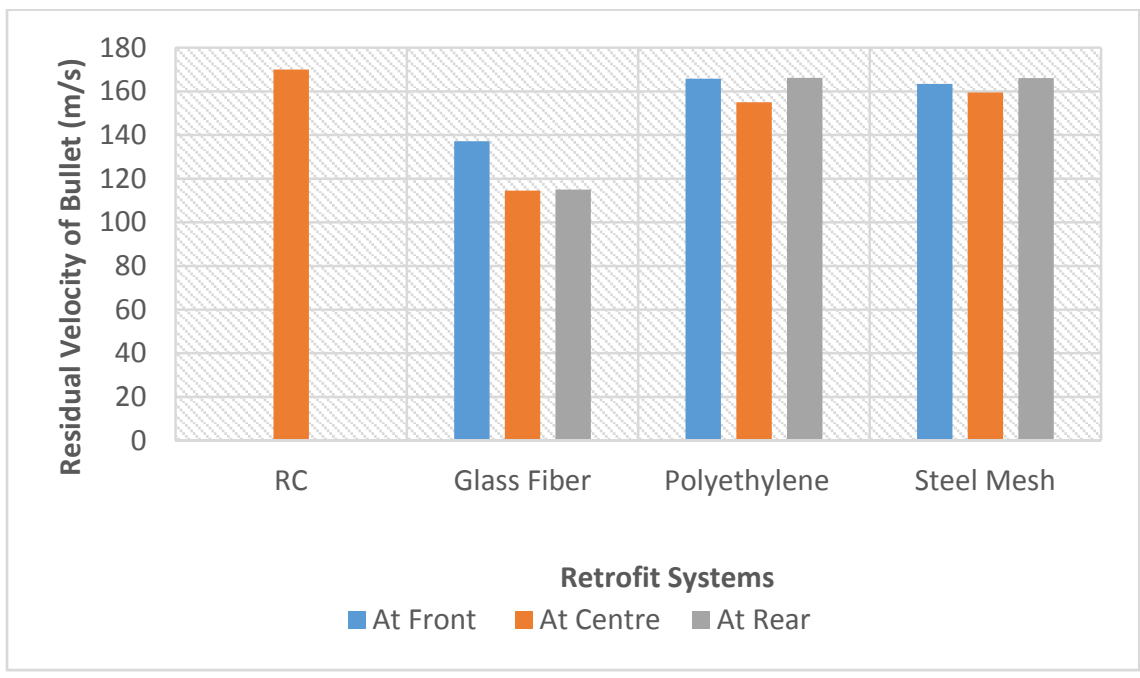

Figure 6: Bullet residual velocity for different retrofit systems. 


\subsection{Kinetic energy and velocity of fragments}

Retrofitting effect on kinetic energy and maximum speed of fragments are listed in Table 4. It can be seen that the reinforced concrete panel retrofitted with one layer of glass fiber at the center (1GF-C) was the best performer when compared with the other retrofits at center (1PE-C and 1SM-C). This type of retrofit increased the energy absorption of the panel and minimized the kinetic energy and speed of the fragments by $54.8 \%$ and $32.8 \%$ respectively. Since the glass fiber retrofit performed better than polyethylene and steel mesh, therefore, two glass fiber retrofits, (2GF-C) and (2GF-C-R), will be considered to investigate the effect of increasing the number of layers. From Table 4, better improvements were obtained when (2GF-C-R) was used. The maximum kinetic energy and speed of the fragments were reduced by $98.0 \%$ and $87 \%$ respectively.

Table 4: Retrofitting effect on kinetic energy and maximum speed of fragments.

\begin{tabular}{|c|c|c|c|c|c|}
\hline No. & Name & $\begin{array}{c}\text { Maximum } \\
\text { fragment } \\
\text { kinetic } \\
\text { energy } \\
(\mathrm{J})\end{array}$ & $\begin{array}{c}\text { Kinetic } \\
\text { energy } \\
\text { reduction } \%\end{array}$ & $\begin{array}{c}\text { Maximum } \\
\text { fragment } \\
\text { speed }(\mathrm{m} / \mathrm{s})\end{array}$ & $\begin{array}{c}\text { Speed } \\
\text { reduction \% }\end{array}$ \\
\hline 1 & $\mathrm{RC}$ & 4.00 & ------- & 170.5 & ------ \\
\hline 2 & $1 \mathrm{GF}-\mathrm{F}$ & 2.59 & $35.0 \%$ & 137.3 & $19.4 \%$ \\
\hline 3 & $1 \mathrm{GF}-\mathrm{C}$ & 1.80 & $54.8 \%$ & 114.6 & $32.8 \%$ \\
\hline 4 & $1 \mathrm{GF}-\mathrm{R}$ & 1.84 & $53.9 \%$ & 115.9 & $32.0 \%$ \\
\hline 5 & $2 \mathrm{GF}-\mathrm{C}$ & 0.41 & $89.8 \%$ & 54.5 & $68.0 \%$ \\
\hline 6 & $2 \mathrm{GF}-\mathrm{C}-\mathrm{R}$ & 0.07 & $98.0 \%$ & 22.3 & $87.0 \%$ \\
\hline 7 & $1 \mathrm{PE}-\mathrm{F}$ & 3.79 & $5.1 \%$ & 166.0 & $2.6 \%$ \\
\hline 8 & $1 \mathrm{PE}-\mathrm{C}$ & 3.33 & $16.7 \%$ & 155.6 & $8.7 \%$ \\
\hline 9 & $1 \mathrm{PE}-\mathrm{R}$ & 3.80 & $4.8 \%$ & 166.3 & $2.4 \%$ \\
\hline 10 & $2 \mathrm{PL}-\mathrm{C}$ & 2.59 & $34.9 \%$ & 137.5 & $19.3 \%$ \\
\hline 11 & $1 \mathrm{SM}-\mathrm{F}$ & 3.68 & $7.7 \%$ & 163.7 & $4.0 \%$ \\
\hline 12 & $1 \mathrm{SM}-\mathrm{C}$ & 3.51 & $12.0 \%$ & 159.8 & $6.2 \%$ \\
\hline 13 & $1 \mathrm{SM}-\mathrm{R}$ & 3.81 & $4.5 \%$ & 166.5 & $2.3 \%$ \\
\hline 14 & $2 \mathrm{SM}-\mathrm{C}$ & 2.91 & $27.0 \%$ & 145.5 & $14.6 \%$ \\
\hline
\end{tabular}

The reinforced concrete panel retrofitted with glass fiber at the center (1GF-C) was selected to show the AUTODYN simulation after the bullet fully penetrated the panel (see Figure 7). 

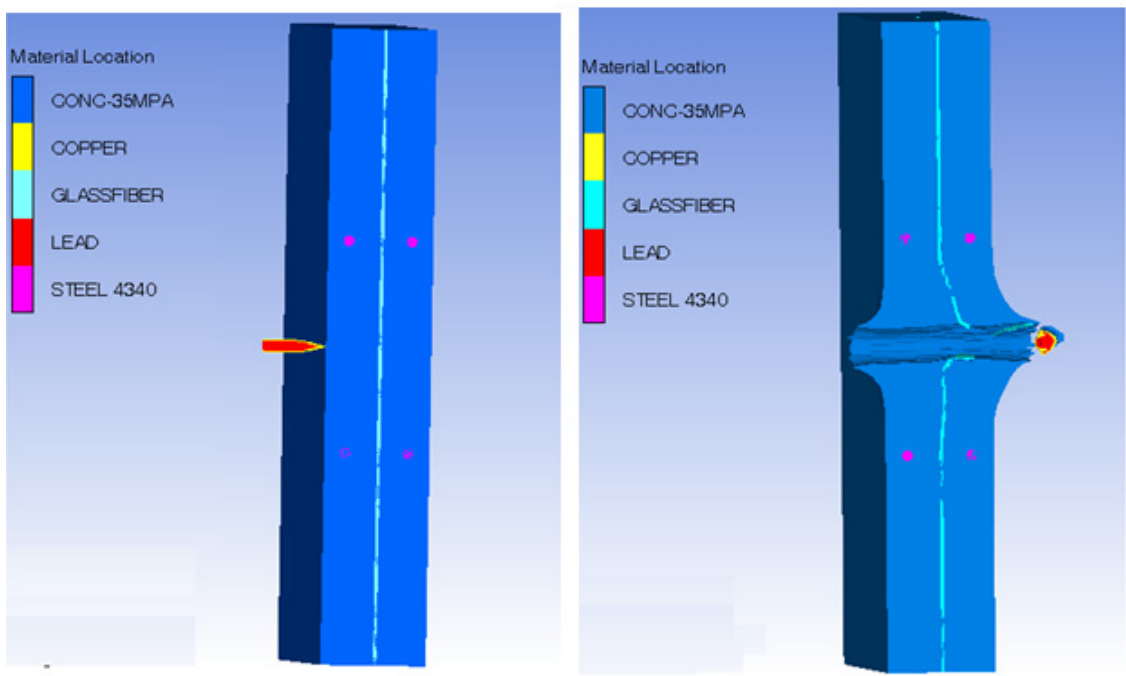

Figure 7: $\quad$ AUTODYN simulation of (1GF-C) panel.

\section{Conclusion}

In this paper, the effectiveness of metallic and non-metallic retrofits on the impact resistance performance of reinforced concrete panels has been investigated. The results clearly showed significant improvement in the performance of the retrofitted panels compared with that of the regular reinforced concrete panel (RC). The retrofitted panels were able to absorb most of the kinetic energy of the bullet and fragments. In particular, panels retrofitted with glass fiber at the center, exhibit higher energy absorbing capacity and reduction in the residual velocity of bullet and fragments when it compared with the polyethylene and steel mesh retrofits. On the other hand, the location and the number of retrofit layers has significant effect on the dissipation of bullet/fragments kinetic energy and reduction of bullet residual velocity.

\section{References}

[1] M.H. Zhang, V.P.W. Shim, G. Lu and C.W. Chew "Resistance of highstrength concrete to projectile impact". International Journal of Impact Engineering, Vol. 31, pp. 825-841, 2005.

[2] F. Vossoughi, C.P. Ostertag, P.J.M. Monterio and G.C. Johnson "Resistance of concrete protected by fabric to projectile impact". Cement and Concrete Research, Vol. 37, pp. 96-106, 2007.

[3] M. Beppu, K. Miwa, M. Itoh, M. Katayama and T. Ohno "Damage evaluation of concrete plates by high velocity impact". International Journal of Impact Engineering, 2008. 
[4] Abdullah , K. Takiguchi, K. Nishimura, S. Hori "Behavior of Ferro-cement Subjected to Missile Impact", "Proceedings of the 17th International Conference on Structural Mechanics in Reactor Technology (SMIRT 17)", Prague, Czech Republic, August 17-22, pp. 1-6, 2003.

[5] M. E. Mohamed, E. M. Eltehawy, I. M. Kamal, and A. Aggour "Numerical Simulation of Projectile Penetration in Reinforced Concrete Panels", 13th International Conference on Aerospace Science and Aviation Technology, ASAT- 13, May 26-28, 2009.

[6] M. Majeed (2011), Enhancing the Mechanical Properties of Concrete Structures Subjected to Impact Loads using Ferro-cement, Ph.D. Dissertation, Carleton University, Ottawa, Canada.

[7] AUTODYN, Theory Manual, Revision 4.3, Century Dynamics Inc., 2005. 